\title{
Effect of ethnicity on mortality of very low birthweight infants in Israel
}

\author{
S Dollberg, F B Mimouni, A Lusky, B Reichman, in collaboration with the Israel \\ Neonatal Network
}

Arch Dis Child Fetal Neonatal Ed 2003;88:F333-F338

See end of article for authors' affiliations

Correspondence to

Dr Dollberg, Department of Neonatology, Lis Maternity Hospital, Tel Aviv Sourasky Medical Center, 6

Weizman Street, Tel Aviv, 64239, Israel;

dollberg@tasmc.health.gov.il

Accepted 2 September 2002

\begin{abstract}
Background: Multiple demographic, genetic, and environmental factors differ between Muslim and Jewish infants in Israel.

Objective: To evaluate whether, after adjustment for perinatal factors associated with mortality, excess mortality occurs in very low birthweight (VLBW) Muslim compared with Jewish infants.

Design: The Israel National VLBW infant database includes data on $99 \%$ of all VLBW births in Israel. The study population comprised 5015 Jewish and 1549 Muslim VLBW infants of more than 23 weeks gestation, born between 1995 and 1999. The Mantel-Haenszel test was used for stratified analysis and logistic regression analysis to assess the effect of ethnic origin on mortality.

Results: The death rate was significantly higher among Muslim infants $(22.7 \%$ v $17.2 \%$; crude odds ratio $1.42 ; 95 \%$ confidence interval 1.24 to 1.63$)$. Excess mortality in Muslims occurred mainly in the $32-33$ week $(8.0 \%$ v $2.8 \%)$ and $>33$ week $(14.7 \%$ v $4.7 \%)$ gestational age groups, and in birthweight groups of $1000-1249 \mathrm{~g}(17.6 \% \vee 9.3 \%)$ and $1250-1500 \mathrm{~g}(9.1 \% \vee 3.6 \%)$. In VLBW infants without congenital malformations, there was a significantly higher risk of mortality among Muslim infants (odds ratio $1.28 ; 95 \%$ confidence interval 1.04 to 1.57 ) compared with Jewish infants, after adjustment for gestational age, birth weight, small for gestational age, prenatal care, prenatal steroid treatment, plurality, mode of delivery, and Apgar score.

Conclusions: Excess mortality was present among Muslim VLBW infants without congenital malformations. Perinatal factors associated with increased risk of mortality were more prevalent in the Muslim VLBW population. The pattern of disparities suggests inadequate access to, or utilisation of, effective perinatal technology in the Muslim population in Israel.
\end{abstract}

T here are significant racial disparities in birth outcome in developed countries such as the United Kingdom, ${ }^{12}$ the United States, ${ }^{3-6}$ and The Netherlands. ${ }^{7}$ In the United States, infant mortality declined more than $45 \%$ overall between 1980 and $2000^{8}$; however, the gap between black and white infants has widened. The reasons for these black-white differences are complex and are not entirely explained by risk factors such as maternal age, education, or socioeconomic status.

In Israel, between 1979 and 2000, infant mortality declined by more than $70 \%$. The rate of decline in mortality was similar in both Jewish infants and infants of other religions; however, mortality among non-Jewish infants has remained approximately twice that of Jewish infants over the years. ${ }^{9}$ This ratio is not consistent across different birth weight groups. For infants of birth weight above $1500 \mathrm{~g}$, the ratio is closer to $3: 1$, whereas among infants weighing $1000-1500 \mathrm{~g}$ it is approximately 1.7:1. Similar death rates have been noted among Jewish and non-Jewish infants of birth weight less than $1000 \mathrm{~g} .{ }^{9}$

In a study on the outcome of Jewish and Bedouin (who are all Muslims) singleton births in Southern Israel, Melamed et $a l^{10}$ found that perinatal mortality of Bedouins was nearly twice that of Jewish neonates, and that the presence of congenital malformations was found to be the strongest predictor of mortality. Ethnicity was no longer a predictor of mortality once congenital malformations were included in a logistic regression model. They concluded that the ethnic differences in mortality in the Bedouin population were fully explained by the presence of congenital anomalies. The higher incidence of congenital anomalies among Bedouins has been attributed to a high rate of consanguinity, low utilisation of prenatal care and diagnostic utilities, and religious or cultural objections to pregnancy termination. ${ }^{11}$ The higher rate of con- genital anomalies was also shown to be associated with consanguineous marriages in a Muslim community in Israel. $^{12}$

An Israel National Bureau of Statistics report on the causes of infant mortality among the various religious/ethnic groups shows that deaths associated with congenital malformations were 2.5-fold higher among infants of other religions, mostly Muslims, than Jewish infants. Mortality caused by immaturity associated conditions were similar, accounting for 1.7 deaths per 1000 live births in both the Jewish and non-Jewish populations. ${ }^{9}$

The Israel National very low birthweight (VLBW) infant database includes data on $99 \%$ of all live birth infants weighing $1500 \mathrm{~g}$ or less. This study evaluates the data in order to assess whether excess mortality occurs among VLBW Muslim infants compared with Jewish infants, after adjustment for perinatal factors associated with mortality.

\section{METHODS}

\section{Study population}

This study is based on analysis of data collected by the Israel Neonatal Network on VLBW newborn infants (birth weight $\leqslant 1500 \mathrm{~g}$ ). All 28 neonatal departments in Israel participate in the data collection, which comprises the Israel National VLBW infant database. For each infant, a prestructured form was filled in at the hospital of birth. The data collected include parental information, maternal pregnancy history and antenatal care, details of the delivery, diagnoses, procedures and

Abbreviations: VLBW, very low birthweight; SGA, small for gestational age; $\mathrm{OR}$, odds ratio; $\mathrm{Cl}$, confidence interval 


\begin{tabular}{|c|c|c|c|c|}
\hline Variable & Categories & $\begin{array}{l}\text { Muslim } \\
\text { (n=1549) (\%) }\end{array}$ & $\begin{array}{l}\text { Jewish } \\
(n=5015)(\%)\end{array}$ & $\mathrm{p}$ Value \\
\hline \multirow{5}{*}{ Week starting prenatal care } & $0-12$ & 59.9 & 83.2 & \\
\hline & $13-20$ & 20.8 & 8.1 & \\
\hline & $>20$ & 4.6 & 1.7 & $<0.001$ \\
\hline & None & 10.3 & 2.3 & \\
\hline & Unknown & 4.5 & 4.8 & \\
\hline \multirow[t]{4}{*}{ Antenatal steroid treatment } & Full & 34.3 & 48.7 & \\
\hline & Partial & 12.4 & 17.3 & $<0.001$ \\
\hline & None & 52.8 & 33.6 & \\
\hline & Unknown & 0.5 & 0.4 & \\
\hline \multirow[t]{2}{*}{ Plurality } & Singleton & 65.2 & 54.4 & $<0.001$ \\
\hline & Multiple & 34.8 & 45.6 & \\
\hline \multirow[t]{2}{*}{ Mode of delivery } & Vaginal & 38.7 & 31.2 & $<0.001$ \\
\hline & C section & 61.3 & 68.8 & \\
\hline \multirow[t]{6}{*}{ Gestational age (weeks) } & $24-25$ & 11.2 & 10.5 & \\
\hline & $26-27$ & 18.7 & 16.7 & \\
\hline & $28-29$ & 25.2 & 23.7 & 0.05 \\
\hline & $30-31$ & 23.7 & 24.3 & \\
\hline & $32-33$ & 13.7 & 15.9 & \\
\hline & $>33$ & 7.5 & 9.0 & \\
\hline \multirow[t]{4}{*}{ Birth weight (g) } & $<500$ & 0.7 & $\begin{array}{l}0.7 \\
11.7\end{array}$ & \\
\hline & & $\begin{array}{l}10.8 \\
21.5\end{array}$ & $\begin{array}{l}11.7 \\
21.0\end{array}$ & NS \\
\hline & $\begin{array}{l}750-999 \\
1000-1249\end{array}$ & $\begin{array}{l}21.5 \\
27.8\end{array}$ & 26.7 & \\
\hline & $1250-1500$ & 39.2 & 39.9 & \\
\hline \multirow[t]{2}{*}{ Intrauterine growth } & SGA & 24.3 & 26.6 & 0.07 \\
\hline & AGA/LGA & 75.7 & 73.4 & \\
\hline \multirow[t]{2}{*}{ Sex } & Male & 51.7 & 50.6 & NS \\
\hline & Female & 48.3 & 49.4 & \\
\hline \multirow[t]{4}{*}{ One minute Apgar score } & $0-3$ & 20.0 & 16.4 & \\
\hline & $4-7$ & 39.6 & 35.8 & $<0.001$ \\
\hline & $8-10$ & 38.0 & 46.3 & \\
\hline & Unknown & 2.3 & 1.6 & \\
\hline \multirow[t]{4}{*}{ Five minute Apgar score } & $0-3$ & 4.6 & 3.2 & \\
\hline & $4-7$ & 19.1 & 15.5 & $<0.001$ \\
\hline & $8-10$ & 72.3 & 77.9 & \\
\hline & Unknown & 4.0 & 3.3 & \\
\hline \multirow[t]{3}{*}{ Congenital malformations } & No & 89.4 & 91.9 & \\
\hline & Yes & 8.8 & 6.9 & 0.01 \\
\hline & Unknown & 1.8 & 1.2 & \\
\hline
\end{tabular}

complications during hospital stay, and outcome at discharge. All departments use an operating manual and standard definitions. Completed forms are checked for logic errors, and if necessary returned to the participating centres for clarification. All liveborn infants in Israel receive a unique identification number at birth. Patient information received by the database coordinator is cross checked with the national birth registry, and missing data on any infant are requested from the hospital of birth. Hospital of birth and patient identification remain confidential by consensus agreement of all participating centres. Data are collected on all infants until death or discharge home.

For the period 1995 to 1999, the Israel National VLBW infant database contains records of 7047 VLBW infants, which comprise $99 \%$ of all VLBW live births in Israel. For the purpose of this analysis, we excluded infants born at less than 24 weeks gestation $(n=316)$, live births following termination of pregnancy $(\mathrm{n}=11)$, and infants whose ethnicity was not Jewish or Muslim $(n=156)$. The study population comprised 5015 Jewish and 1549 Muslim infants. All 28 birthing centres in Israel have tertiary care facilities. Only $44(2.8 \%)$ of the Muslim and 170 (3.4\%) of the Jewish infants were transferred from their hospital of birth.

\section{Data variables}

For the purpose of data collection and analysis, the following definitions and categories were used. Ethnicity was defined according to the mother's ethnic/religious group as reported on the infant's birth certificate. This includes Jewish, Muslim, Druze, Christian, and other groups. Prenatal care was categorised as starting in weeks $0-12,13-20,>20$ weeks, or none. Antenatal steroid treatment was defined as "incomplete" if delivery occurred less than 24 hours after the first dose or more than one week after the last dose, and "complete" if delivery occurred more than 24 hours and less than seven days after a complete course of treatment. Small for gestational age (SGA) was defined as birth weight more than 2 standard deviations below the mean weight, according to the intrauterine growth curves of Usher and Mclean. ${ }^{13}$ Congenital malformations were recorded according to the list of reportable 
Table 2 Mortality risk of Muslim compared with Jewish very low birthweight infants stratified by perinatal variable

\begin{tabular}{|c|c|c|c|c|}
\hline Variable & $\begin{array}{l}\text { Muslim } \\
\text { ( } n=1549)(\% \\
\text { mortality) }\end{array}$ & $\begin{array}{l}\text { Jewish } \\
\text { (n=5015) (\% } \\
\text { mortality) }\end{array}$ & $\mathrm{p}$ Value & $\begin{array}{l}\text { Mantel-Haenszel OR } \\
(95 \% \mathrm{CI})\end{array}$ \\
\hline Total & 22.6 & 17.2 & $<0.01$ & \\
\hline \multicolumn{5}{|c|}{ Week starting prenatal care } \\
\hline 0-12 & 20.5 & 16.1 & $<0.01$ & \multirow{4}{*}{1.3 (1.1 to 1.4 ) } \\
\hline $13-20$ & 24.2 & 15.1 & $<0.01$ & \\
\hline$>20$ & 31.0 & 19.0 & 0.09 & \\
\hline None & 23.9 & 34.2 & 0.06 & \\
\hline \multicolumn{5}{|c|}{ Antenatal steroid treatment } \\
\hline Full course & 16.0 & 11.7 & 0.01 & \multirow{3}{*}{$1.2(1.1 \text { to } 1.3)^{*}$} \\
\hline Partial course & 13.0 & 18.3 & 0.08 & \\
\hline No prenatal steroids & 29.3 & 24.3 & 0.01 & \\
\hline \multicolumn{5}{|l|}{ Multiple birth } \\
\hline Singleton & 23.8 & 18.2 & $<0.01$ & \multirow[b]{2}{*}{1.3 (1.2 to 1.5$)$} \\
\hline Multiple & 20.8 & 15.9 & 0.01 & \\
\hline \multicolumn{5}{|l|}{ Mode of delivery } \\
\hline Vaginal & 29.8 & 26.4 & 0.10 & \multirow[b]{2}{*}{1.3 (1.1 to 1.4$)$} \\
\hline Caesarean section & 18.2 & 13.0 & $<0.01$ & \\
\hline \multicolumn{5}{|l|}{ Gestational age (weeks) } \\
\hline $24-25$ & 71.7 & 69.7 & 0.62 & \multirow{6}{*}{1.3 (1.1 to 1.4 ) } \\
\hline $26-27$ & 33.8 & 26.4 & 0.02 & \\
\hline $28-29$ & 16.9 & 13.6 & 0.10 & \\
\hline $30-31$ & 8.2 & 5.6 & 0.07 & \\
\hline $32-33$ & 8.0 & 2.8 & $<0.01$ & \\
\hline$>33$ & 14.7 & 4.7 & $<0.01$ & \\
\hline \multicolumn{5}{|l|}{ Birth weight (g) } \\
\hline$<500$ & 100.0 & 81.8 & 0.15 & \multirow{5}{*}{1.4 (1.2 to 1.5$)$} \\
\hline $500-749$ & 62.9 & 64.0 & 0.79 & \\
\hline $750-999$ & 31.8 & 24.8 & 0.01 & \\
\hline $1000-1249$ & 17.6 & 9.3 & $<0.01$ & \\
\hline $1250-1500$ & 9.1 & 3.6 & $<0.01$ & \\
\hline \multicolumn{5}{|l|}{ Intrauterine growth } \\
\hline AGA/LGA & 23.6 & 16.7 & $<0.01$ & \multirow[t]{2}{*}{1.3 (1.2 to 1.5$)$} \\
\hline SGA & 19.9 & 18.4 & 0.49 & \\
\hline \multicolumn{5}{|l|}{ Congenital malformations } \\
\hline No & 20.6 & 15.2 & $<0.01$ & \multirow[t]{2}{*}{1.3 (1.2 to 1.5$)$} \\
\hline Yes & 28.7 & 29.6 & 0.84 & \\
\hline $\begin{array}{l}\text { * No homogeneity was } \\
\text { OR, Odds ratio; Cl, cor } \\
\text { gestational age; LGA, I }\end{array}$ & $\begin{array}{l}\text { strata. } \\
\text { al; SGA, smo } \\
\text { tional age. }\end{array}$ & gestational & $A G A, a$ & priate size for \\
\hline
\end{tabular}

malformations required in Israel, which includes all major congenital malformations. Mortality was defined as death before discharge from hospital. ${ }^{14}$

\section{Statistical analysis}

Differences in the perinatal characteristics between Muslim and Jewish infants and the percentage mortality among strata of selected characteristics were tested by the $\chi^{2}$ test for proportions. The Mantel-Haenszel test was used to estimate the common odds ratio (OR) for mortality of Muslim compared with Jewish infants. Multiple logistic regression analyses were used to evaluate the association between ethnic group and mortality after controlling for confounding variables. Results of the logistic models are presented as adjusted OR and 95\% confidence interval (CI). Goodness of fit of the models was estimated by Hosmer and Lemeshow statistics. Analyses were performed using the SAS statistical software version 8.2 (SAS Institute, Inc, Cary, North Carolina, USA).

\section{RESULTS}

The study population comprised 6564 VLBW infants; 5015 $(76 \%)$ were Jewish and 1549 (24\%) were Muslims. Table 1 compares the perinatal factors in the two groups. Prenatal care was initiated earlier, and exposure to prenatal steroid treatment, multiple births, and caesarean section deliveries were significantly higher in Jewish infants. The birthweight distribution was similar, although the Muslim infants tended to be of lower gestational age $(\mathrm{p}=0.05)$. The percentage of infants with congenital malformations was significantly higher in Muslims $(8.8 \% v 6.9 \% ; p=0.01)$, and the Muslim infants had lower Apgar scores at birth $(\mathrm{p}<0.001)$. The impact of outborn versus inborn status on mortality was not significant. Among Muslims, mortality was $20.5 \%$ in outborn infants compared with $22.8 \%$ in inborns, and in Jewish infants, it was $18.2 \%$ compared with $17.1 \%$ respectively.

To assess possible interactions for mortality, a stratified analysis of perinatal risk factors was performed (table 2 ). The overall mortality among the Muslim infants was $22.6 \%$ compared with $17.2 \%$ among Jewish infants (crude OR 1.42, 95\% CI 1.24 to 1.63 ). There were significant differences in mortality between Muslims and Jews at the gestational ages of 26-27 weeks and $>31$ weeks. There were no differences in mortality between the groups of birth weight $<750$ g, but mortality in the Muslims was higher than in Jewish infants in all other birthweight categories. Infant mortality was similar in Muslim and Jewish infants born to mothers who did not receive prenatal care; however, mortality was higher in Muslim infants whose mothers attended prenatal care, regardless of the week in which prenatal care was started. Although prenatal steroid treatment affected mortality in both groups, excess mortality occurred in Muslim compared with Jewish infants who received either a complete course or no prenatal steroid treatment. Mortality among infants with congenital malformations was about $29 \%$ in both groups, but in infants without congenital malformations it was significantly higher in Muslim infants $(20.6 \%)$ than in the Jewish group (15.2\%) (OR 1.3 ; $95 \%$ CI 1.2 to 1.5 ). 
Table 3 Multiple logistic regression analyses of risk of mortality of Muslim compared with Jewish very low birthweight infants adjusted for potential perinatal risk factors

\begin{tabular}{|c|c|c|}
\hline Variable & Total group $(n=6474)$ & $\begin{array}{l}\text { Excluding malformations } \\
(\mathrm{n}=5992)\end{array}$ \\
\hline \multicolumn{3}{|l|}{ Ethnicity } \\
\hline Muslim & 1.18 (0.98 to 1.43 ) & 1.28 (1.04 to 1.57 ) \\
\hline Jewish & 1.0 & 1.0 \\
\hline \multicolumn{3}{|l|}{ Week starting prenatal care } \\
\hline $0-12$ & 1.0 & 1.0 \\
\hline $13-20$ & 1.18 (0.91 to 1.52$)$ & 1.06 (0.79 to 1.39 ) \\
\hline$>20$ or no prenatal care & 1.67 (1.23 to 2.24$)$ & 1.45 (1.03 to 2.02 ) \\
\hline Unknown & 2.51 (1.77 to 3.53$)$ & 2.45 (1.65 to 3.59$)$ \\
\hline \multicolumn{3}{|l|}{ Antenatal steroid treatment } \\
\hline Yes & 1.0 & 1.0 \\
\hline Partial & 1.04 (0.82 to 1.31$)$ & 0.97 (0.75 to 1.24$)$ \\
\hline None & 1.89 (1.58 to 2.27 ) & 1.80 (1.48 to 2.19$)$ \\
\hline Unknown & $1.11 \quad(0.30$ to 3.46$)$ & 1.23 (0.31 to 4.12$)$ \\
\hline \multicolumn{3}{|l|}{ Plurality } \\
\hline Singleton & 1.0 & 1.0 \\
\hline Multiple & 1.30 (1.10 to 1.54$)$ & 1.32 (1.10 to 1.59 ) \\
\hline \multicolumn{3}{|l|}{ Mode of delivery } \\
\hline Vaginal & 1.0 & 1.0 \\
\hline Caesarean section & 0.55 (0.46 to 0.65$)$ & $0.57(0.47$ to 0.68$)$ \\
\hline \multicolumn{3}{|l|}{ Gestational age } \\
\hline (Decrease of 1 week) & 1.27 (1.19 to 1.35$)$ & 1.41 (1.31 to 1.52$)$ \\
\hline \multicolumn{3}{|l|}{ Birth weight } \\
\hline (Decrease of $100 \mathrm{~g}$ ) & 1.33 (1.25 to 1.42$)$ & 1.31 (1.22 to 1.41$)$ \\
\hline \multicolumn{3}{|l|}{ Intrauterine growth } \\
\hline AGA/LGA & 1.0 & 1.0 \\
\hline SGA & 1.48 (1.11 to 1.98$)$ & 1.54 (1.12 to 2.12 ) \\
\hline \multicolumn{3}{|l|}{ Sex } \\
\hline Female & 1.0 & 1.0 \\
\hline Male & 1.28 (1.09 to 1.50$)$ & 1.37 (1.15 to 1.63 ) \\
\hline \multicolumn{3}{|l|}{ One minute Apgar score } \\
\hline $0-3$ & 4.12 (3.27 to 5.20$)$ & 3.46 (2.68 to 4.45$)$ \\
\hline $4-7$ & 2.03 (1.65 to 2.50$)$ & 1.80 (1.43 to 2.25$)$ \\
\hline$>7$ & 1.0 & 1.0 \\
\hline Unknown & 2.32 (1.39 to 3.81$)$ & 1.87 (1.06 to 3.23 ) \\
\hline \multicolumn{3}{|l|}{ Congenital malformations } \\
\hline No & 1.0 & Excluded \\
\hline Yes & 3.85 (2.96 to 5.00$)$ & \\
\hline Goodness of fit test & 0.99 & 0.33 \\
\hline
\end{tabular}

Values are odds ratio ( $95 \%$ confidence interval).
SGA, small for gestational age; AGA, appropriate size for gestational age; LGA, large for gestational age

The risk of mortality in Muslim infants compared with Jewish infants, adjusted for potential prenatal risk factors, was evaluated by multiple logistic regression analysis. Because of the significant impact of congenital malformations on mortality and the different rate of malformations in the two groups, separate logistic models, including and excluding infants with malformations were performed as shown in table 3. In the model that included infants with congenital malformations, the presence of malformations was associated with excess mortality (OR 3.85; 95\% CI 2.96 to 5.00). Possible interaction between ethnic origin and malformations was considered and entered into the logistic model. The interaction was not significant (OR 1.27, 95\% CI 0.73 to 2.21). Ethnic origin had no additional significant effect on mortality (OR 1.18; $95 \%$ CI 0.98 to 1.43 ), possibly because of the association between ethnicity and congenital malformations. In the analysis that included only infants without congenital malformations, 348 Jewish and 136 Muslim infants were excluded. In this model, the adjusted OR for mortality among Muslim infants was 1.28 (95\% CI 1.04 to 1.57). Furthermore, in both logistic models, mortality among VLBW infants was significantly affected by late or no prenatal care, no prenatal steroid treatment, decrease in birth weight and gestational age, SGA, caesarean delivery, male sex, and multiple births. Hosmer-Lemeshow goodness of fit statistics showed that the models fitted well, with p values of 0.99 and 0.33 respectively (table 3 ).

\section{DISCUSSION}

This population based study evaluated mortality among Muslim and Jewish VLBW infants in Israel, highlighting a number of important differences between the two populations. We show that mortality was significantly influenced by ethnicity, and was higher in Muslim than Jewish infants. The difference in mortality remained significant in a logistic regression model, taking into account the potential confounders that differed significantly between the two groups in a univariate analysis. Furthermore, excess mortality among Muslim VLBW infants could not be explained by the higher incidence of congenital malformations in the population.

Significant differences were present in the perinatal characteristics of Jewish and Muslim VLBW infants, which may have an appreciable effect on mortality. Almost half of Jewish VLBW infant births were multiple compared with 35\% of Muslim. This may be due to differences in the use of assisted reproduction services, which is very high in Israel: in $1996,2.1 \%$ of all deliveries were the product of in vitro fertilisation, and the rate is rising rapidly. ${ }^{15}$ This difference in multiple births may account for, at least partially, the difference noted in the gestational age at which prenatal care was initiated, prenatal steroid treatment, and caesarean deliveries.

Prenatal steroid treatment was more prevalent in Jews than in Muslims, possibly because of a delay in the diagnosis of preterm delivery. ${ }^{16}$ Bronstein and Goldenberg ${ }^{17}$ have suggested that no prenatal care and short intervals between admission 
and delivery are associated with less steroid use. We speculate that Muslim women, who more often live in small rural villages remote from the birthing centres, may delay seeking medical care. They received prenatal care less frequently and later in the course of pregnancy than Jewish women, despite the fact that prenatal care is available and generally easily accessible in most Muslim villages and cities. Equal access to health care in Israel is provided by the National Health Insurance Law. ${ }^{18}$ However, it has been reported that Israeli Arabs use preventive medicine less often than Jews, and more Arabs reported forgoing medical services because of the distances involved. ${ }^{16}$

In the univariate analysis, significantly higher mortality in Muslim infants was noted especially in the higher birthweight and gestational age groups. In the extremely low birthweight and low gestational age groups, mortality was very high in both Muslim and Jewish infants. However, the smaller sizes of these gestational age and birthweight groups may have made any differences non-significant. The pattern is, however, consistent with the Israeli national infant mortality statistics, which show that differences in mortality between Muslim and Jewish infants are greater in the higher birthweight groups. ${ }^{19}$ Interestingly, the excess mortality in the Muslim infants was present in the infants of appropriate size for gestational age but not the SGA infants. The Israel National VLBW infant database is a birthweight defined cohort, resulting in an excess of SGA infants, who accounted for $25 \%$ of the total population. As SGA mortality did not differ by ethnicity, in contrast with the higher mortality among Muslim infants of appropriate size for gestational age, the cohort studied underestimates the racial disparity.

Excess congenital malformations in Muslims have been previously documented ${ }^{11}$ and have been attributed to a high rate of consanguineous marriages, ${ }^{21}$ low use of prenatal diagnosis, ${ }^{22}$ and religious or cultural objection to pregnancy termination. ${ }^{11}{ }^{23-25}$ The high mortality among VLBW infants with birth defects has been reported ${ }^{26}$ and in our study about $29 \%$ of VLBW infants with congenital malformations died in both the Jewish and Muslim groups. Among infants without congenital malformations, the mortality in Muslims was, however, significantly higher than in the equivalent Jewish group. The ethnic disparity in congenital anomalies in our study was 1.9 percentage points, and the differential mortality was negligible $(28.7 \% \vee 29.6 \%)$. Thus, although congenital anomalies are a potent risk factor for mortality (OR 3.85), they do not provide an explanation for the ethnic mortality disparity.

The results of this study show excess mortality among Muslim VLBW infants without congenital malformations in Israel. Furthermore, perinatal factors significantly associated with an increased risk of mortality, such as late or no prenatal care and lack of antenatal steroid treatment, were more prevalent in the Muslim population. Many attempts to explain racial disparities in infant mortality have been made. ${ }^{1-7} \mathrm{~A}$ variety of factors have been considered, including socioeconomic inequalities, teenage pregnancies and multiparity, the quality of and access to perinatal health care, and the rate of congenital malformations. Recently, ethnic differences in the effectiveness of surfactant therapy have been reported, resulting in a greater decline in mortality in white than in black preterm infants. ${ }^{45}$ There appears to be no simple explanation for ethnic differences in mortality, and recommendations to remedy these disparities are usually speculative. As pointed out by Pearson, ${ }^{27}$ the relative significance of "genetic, environmental or therapeutic factors is not easily untangled. It is, however, imperative that services of high quality are available, attractive, accessible and appropriate for all women, in order that problems are prevented or detected early." This obviously must be pursued in an effective and culturally sensitive manner.

The implications of this study in terms of what is remediable are complex and limited in view of the data avail- able. The pattern of ethnic disparities shown does, however, suggest inadequate access to or utilisation of effective perinatal technology. We speculate that the rural geographic distribution of the Muslim population, often distant from major birthing centres, may contribute to a delay in the diagnosis of premature labour, a short interval between admission and delivery, and hence the inadequate antenatal steroid treatment noted. Intervention programmes directed at improving access to, and utilisation of, available prenatal and perinatal care services, as well as efforts to reduce the prevalence of congenital malformations, may help to further reduce mortality among VLBW infants of Muslim ethnic origin in Israel.

\section{ACKNOWLEDGEMENTS}

The Israel National Very Low Birthweight Infant Database is partially funded by the Israel Center for Disease Control and the Ministry of Health.

The Israel Neonatal Network participating centres in the Israel National VLBW infant database are:

Assaf Harofeh Medical Center, Rishon Le Zion

Barzilay Medical Center, Ashkelon

Bikur Holim Hospital, Jerusalem

Bnei Zion Medical Center, Haifa

Carmel Medical Center, Haifa

English (Scottish) Hospital, Nazareth

French Hospital, Nazareth

Hadassah University Hospital Ein-Karem, Jerusalem

Hadassah University Hospital Har Hazofim, Jerusalem

Haemek Medical Center, Afula

Hillel Yafe Medical Center, Hadera

Italian Hospital, Nazareth

Kaplan Hospital, Rehovot

Laniado Hospital, Netanya

Maayanei Hayeshua Hospital, Bnei-Brak

Meir Medical Center, Kefar Saba

Misgav Ladach Hospital, Jerusalem

Naharia Hospital, Naharia

Poria Hospital, Tiberias

Rambam Medical Center, Haifa

Rivka Ziv Hospital, Zefat

Schneider Children's Medical Center of Israel and Rabin Medical Center (Beilinson Campus), Petach-Tikva

Shaare-Zedek Hospital, Jerusalem

Sheba Medical Center, Tel-Hashomer

Soroka Medical Center, Beer-Sheva

Sourasky Medical Center, Tel-Aviv

Wolfson Medical Center, Holon

Yoseftal Hospital, Eilat

Coordinating Center: Mother and Child Research Unit, Gertner Institute, Tel Hashomer

Authors' affiliations

S Dollberg, F B Mimouni, Department of Neonatology, Lis Maternity Hospital, Tel Aviv Sourasky Medical Center, Tel Aviv, Israel

S Dollberg, F B Mimouni, B Reichman, Sackler Faculty of Medicine, Tel Aviv University

A Lusky, B Reichman, Mother and Child Research Unit, Gertner

Institute, Tel Hashomer, Israel

\section{REFERENCES}

1 Lyon AL, Clarkson P, Jeffry I, et al. Effect of ethnic origin of the mother on fetal outcome. Arch Dis Child 1994;70:F40-3.

2 Terry PB, Condie RG, Bissenden JG, et al. Ethnic differences in incisdence of very low birth weight and neonatal deaths among normally formed infants. Arch Dis Child 1987;62:709-11

3 Demissie K, Rhoads GG, Ananth CV, et al. Trends in preterm birth and neonatal mortality among blacks and whites in the United States from 1989 to 1997. Am J Epidemiol 2001:154:307-15.

4 Ranganathan D, Wall S, Khoshnood B, et al. Racial differences in respiratory-related neonatal mortality among very low birth weight infants. J Pediatr 2000;136:454-9.

5 Malcoe LH, Shaw GM, Lammer EJ, et al. The effect of congenital anomalies on mortality risk in white and black infants. Am J Public Health 1999;89:887-92. 
6 Hamvas A, Wise PH, Yang RK, et al. The influence of the wider use of surfactant therapy on neonatal mortality among blacks and whites. $N$ Engl J Med 1996;334:1635-40

7 Schulpen TW, van Steenbergen JE, van Driel HF. Influence of ethnicity on perinatal and child mortality in the Netherlands. Arch Dis Child 2001:84:222-6.

8 Centers for Disease Control and Prevention. Infant mortality and low birth weight among black and white infants, United States, 1980-2000. MMWR Morb Mortal Wkly Rep 2002;51:589-92.

9 Israeli Ministry of Health and the State of Israel Central Bureau of Statistics. Infant mortality 1993-1996; sociodemographic characteristics. Jerusalem: Central Bureau of Statistics, 2000:publication number 1127.

10 Melamed Y, Bashiri A, Shoham-Vardi I, et al. Differences in preterm delivery rates and outcomes in Jews and Bedouins in Southern Israel. Eur J Obstet Gynecol Reprod Biol 2000;93:41-6.

11 Sheiner E, Shoham Vardi I, Weitzman E, et al. Decisions regarding pregnancy termination among Bedouin couples referred to third level ultrasound clinic. Eur J Obstet Gynecol Reprod Biol 1998;76:141-6.

12 Jaber L, Merlob P, Gabriel R, et al. Effects of consanguineous marriage on reproductive outcome in an Arab community in Israel. J Med Genet 1997;34:1000-2.

13 Usher R, McLean F. Intrauterine growth of live-born Caucasian infants at sea level: standards obtained from measurements in 7 dimensions of infants born between 25 and 44 weeks of gestation. J Pediatr 1969:74:901-10.

14 Costeloe K, Hennessy E, Gibson AT, et al. The EPICure study: outcomes to discharge from hospital for infants born at the threshold of viability. Pediatrics 2000;106:659-71.
15 Medical Administration Publication, Ministry of Health of Israel 2000. http://www.health.gov.il/units/healthisrael/160.htm

16 Gross R, Rosen B, Shirom A. Reforming the Israeli health system: findings of a 3-year evaluation. Health Policy 2001;56:1-20.

17 Bronstein JM, Goldenberg RL. Practice variation in the use of corticosteroids: a comparison of 8 data sets. Am J Obstet Gynecol $1995 ; 173: 296-8$

18 State of Israel. National Health Insurance Law 1994.

19 Central Bureau of Statistics, State of Israel. Statistical abstract of Israel. Jerusalem: Central Bureau of Statistics, 2000: No 51.

20 Zlotogora J. Genetic disorders among Palestinian Arabs. Am J Med Genet 1997; 11:33-5.

21 Jaber L, Merlob P, Rotter Jl, et al. Marked parental consanguinity as a cause for increased major malformations in an Israeli Arab community Am J Med Genet 1992;44: 1-6.

22 Jaber L, Dolfin T, Shohat T, et al. Prenatal diagnosis for detecting congenital malformations: acceptance among Israeli Arab women. Isr Med Assoc J 2000;2:346-50

23 Gatard AR. Attitudes and beliefs of Muslim mothers towards pregnancy and infancy. Arch Dis Child 1994;71:170-4.

24 El-Hashemite $\mathbf{N}$. The Islamic view in genetic preventive procedures. Lancet 1997;350:223.

25 Jaber L. Consanguineous marriages: demographic and medical aspects. Harefuah 1993;124:235-6.

26 Suresh GK, Horbar JD, Kenny M, et al. Major birth defects in very low birth weight infants. J Pediatr 2001;139:366-73.

27 Pearson M. Ethnic differences in infant health. Arch Dis Child 1991:66:88-90. 